\title{
Transplacental Carcinogenesis
}

National Cancer Institute

\section{Source}

National Cancer Institute. Transplacental Carcinogenesis. NCI Thesaurus. Code C19086.

Studies of the mechanisms of induction of cancer in an individual by in utero exposure to a carcinogen. 